\title{
Sport and physical activity following unicompartmental knee arthroplasty: a systematic review
}

\author{
Wenzel Waldstein ${ }^{1} \cdot$ Paul Kolbitsch $^{1} \cdot$ Ulrich Koller $^{1} \cdot$ Friedrich Boettner $^{2}$ • \\ Reinhard Windhager ${ }^{1}$
}

Received: 3 January 2016 / Accepted: 10 May 2016 / Published online: 21 May 2016

(C) The Author(s) 2016. This article is published with open access at Springerlink.com

\begin{abstract}
Purpose Unicompartmental knee arthroplasty (UKA) can be a surgical treatment option for patients with high expectations regarding the post-operative level of physical activity. A systematic review was undertaken to answer three research questions: (1) is there an improvement of physical activity based on validated activity scores following UKA? (2) What are the sport disciplines and the sport patterns of UKA patients? (3) What are the pre- and post-operative sport participation rates and the return to activity rates of UKA patients?

Methods Following the PRISMA guidelines, EMBASE, MEDLINE, ISI Web of Science and the Cochrane Central Register of Controlled Trials were searched for studies reporting the level of sport and/or physical activity before and after UKA, and/or included at least one activity score before and after UKA.

Results Seventeen studies were identified reporting on 2972 UKAs, of which $89 \%$ were medial UKAs and $92 \%$ were mobile-bearing implants, respectively. Ten studies reported a statistically significant improvement of physical activity following UKA according to the UCLA activity score, the Tegner activity score or the High Activity Arthroplasty Score, respectively. Hiking, cycling and swimming are the most common activities following UKA. Sport participation before the onset of restricting symptoms ranged
\end{abstract}

Wenzel Waldstein

wwaldstein@gmail.com

1 Department of Orthopaedics, Vienna General Hospital, Medical University of Vienna, Waehringer Guertel 18-20, 1090 Vienna, Austria

2 Adult Reconstruction and Joint Replacement Division, Hospital for Special Surgery, New York, NY, USA from 64 to $93 \%$ and slightly decreased by $2-9 \%$ following UKA. The return to activity rate ranged from 87 to $98 \%$. Conclusion Patients following UKA are physically active according to validated activity scores. A significant increase in low-impact activities and a decrease in high-impact activities after UKA was observed. Patients with a UKA regularly participate in sports; however, sport participation slightly decreased compared to pre-arthritic levels. This systematic review helps physicians to manage the expectations of patients regarding the level of physical activity following UKA.

Level of evidence III.

Keywords Unicompartmental knee arthroplasty · Sport · Physical activity $\cdot$ Review

\section{Introduction}

Knee osteoarthritis (OA) is a frequent cause of pain and disability in the elderly [6, 9, 39]. Epidemiologic studies suggest that almost half of the general US population may develop symptomatic knee OA by the age of 85 years, with a particularly high risk in the obese [23]. The demand for primary knee arthroplasties is, therefore, projected to grow by more than $600 \%$ by 2030 [20].

Unicompartmental knee arthroplasty (UKA) is an effective and safe treatment option for isolated end-stage medial or lateral compartment knee OA [5, 28]. Kozinn and Scott [19] proposed indications and contraindications for fixedbearing UKAs. The authors postulated that damage to the patellofemoral joint, obesity, youth and high activity levels should be considered a contraindication for a UKA. However, for mobile-bearing implants most of these contraindications may be neglected. The Oxford group [24] proposed 
to consider an Oxford UKA in all knees with bone-onbone arthritis [11], full-thickness cartilage in the contralateral compartment [11], a fully correctible intra-articular deformity [42] and an intact anterior cruciate ligament [43, 48]. Patellofemoral arthritis is no contraindication unless deep eburnation, bone loss or patellar subluxation is observed [24]. These criteria are satisfied in a significant proportion of knees requiring arthroplasty. For fixed-bearing UKAs, the indications are less defined. Deschamps and Chol [7] suggested that for modern fixed-bearing implants, indications are slightly stricter than for mobile-bearing implants with anterior knee pain and a body mass index above $30 \mathrm{~kg} / \mathrm{m}^{2}$ being a (relative) contraindication.

For both UKA design concepts, excellent clinical results and improved survivorship have been reported [16, 27, 31, 40, 41, 46]. Consequently, UKAs are increasingly being used in younger and more active patients $[2,3]$. This particular patient cohort, however, has high expectations concerning the post-operative level of physical activity $[4,8]$.

Conventional outcome scores such as the American Knee Society Score [17] assess objective parameters and what a patient is capable of doing. However, these rating scales do not take into account what a patient is actually doing [51]. In times of high post-operative expectations, activity rating scales are becoming a key factor to assess the outcome of a procedure. There has been no review analysing all available studies with regard to pre- and post-operative activity scores following UKA. Therefore, the present study undertook a systematic review analysing the level of sport and physical activity following UKA. The following research questions were asked: (1) is there an improvement of physical activity based on validated activity scores following UKA? (2) What are the sport disciplines and the sport patterns of UKA patients? (3) What are the pre- and post-operative sport participation rates and the return to activity rates of UKA patients?

\section{Materials and methods}

EMBASE, MEDLINE and the ISI Web of Science for randomized controlled trials, quasi-randomized trials and controlled clinical trials as well as case series investigating the clinical outcome of UKAs with regard to physical activity and sport were searched. The inclusion criteria were defined as follows: studies reporting on the level of physical activity or sport before and after UKA using an activity score or an activity questionnaire. A combination of Medical Subject Headings (MESH) terms and free text was used to search for relevant studies. Studies in English or German language were identified ("Appendix").

Two authors (P.K. and W.W.) reviewed all abstracts. The full text was analysed for studies meeting the inclusion criteria. The systematic review was conducted according to the preferred reporting items for systematic reviews and meta-analyses (PRISMA) guidelines [22]. The methodological index for non-randomized studies (MINORS) was used to assess the quality of all studies [34] (Table 1).

Data were extracted using a standardized form, including patient demographics follow-up period, type of implant, and scores or questionnaires assessing pre- and post-operative activity levels. The same activity score had to be performed pre-operatively and at least one time postoperatively. There were no restrictions regarding type of score used. Duplicate articles and studies not reporting on the same pre- and post-operative scores were excluded. Additional information regarding physical activity or sport before and after UKA was documented, and used for further interpretation of the results.

\section{Statistical analysis}

Descriptive statistics for the included studies were presented.

\section{Results}

Three hundred and thirty-six studies were identified in the search. Additional eight studies were identified through cross-referencing. After exclusion of duplicates, a total of 250 papers were screened for applicability (Fig. 1). One study by Streit et al. [37] in 2012 reported on the same cohort as Walker et al. [44] in 2015; the study of Streit et al. [37] was therefore excluded from this review. Another study by Streit et al. [36] was not considered as it analysed the same cohort as Walker et al. [45]. Ultimately, 17 studies were included in the final analysis. These 17 studies reported on 2972 UKAs in 2636 patients. The patients' age ranged from 25 to 92 years (Table 1). The majority of cases (89 \%, 2653 of 2972) were medial UKAs; $11 \%$ (319 of 2972) were lateral UKAs. One study analysing 41 UKAs did not specify whether a medial or lateral UKA was performed [16]. The mean MINORS score was of 11/16 points for single-arm studies $(n=12)$ and 16/24 points for comparative studies $(n=5)$ (Table 2).

\section{Activity scores}

Thirteen of seventeen studies used validated activity scores to evaluate the pre- and post-operative level of physical activity. Ten of these studies reported a statistically significant improvement following UKA according to the UCLA activity score [51], the Tegner activity score [38] or the High Activity Arthroplasty Score [1, 10, 15, 18, 21, 26, 30, 44, 45, 47] (Table 3). 


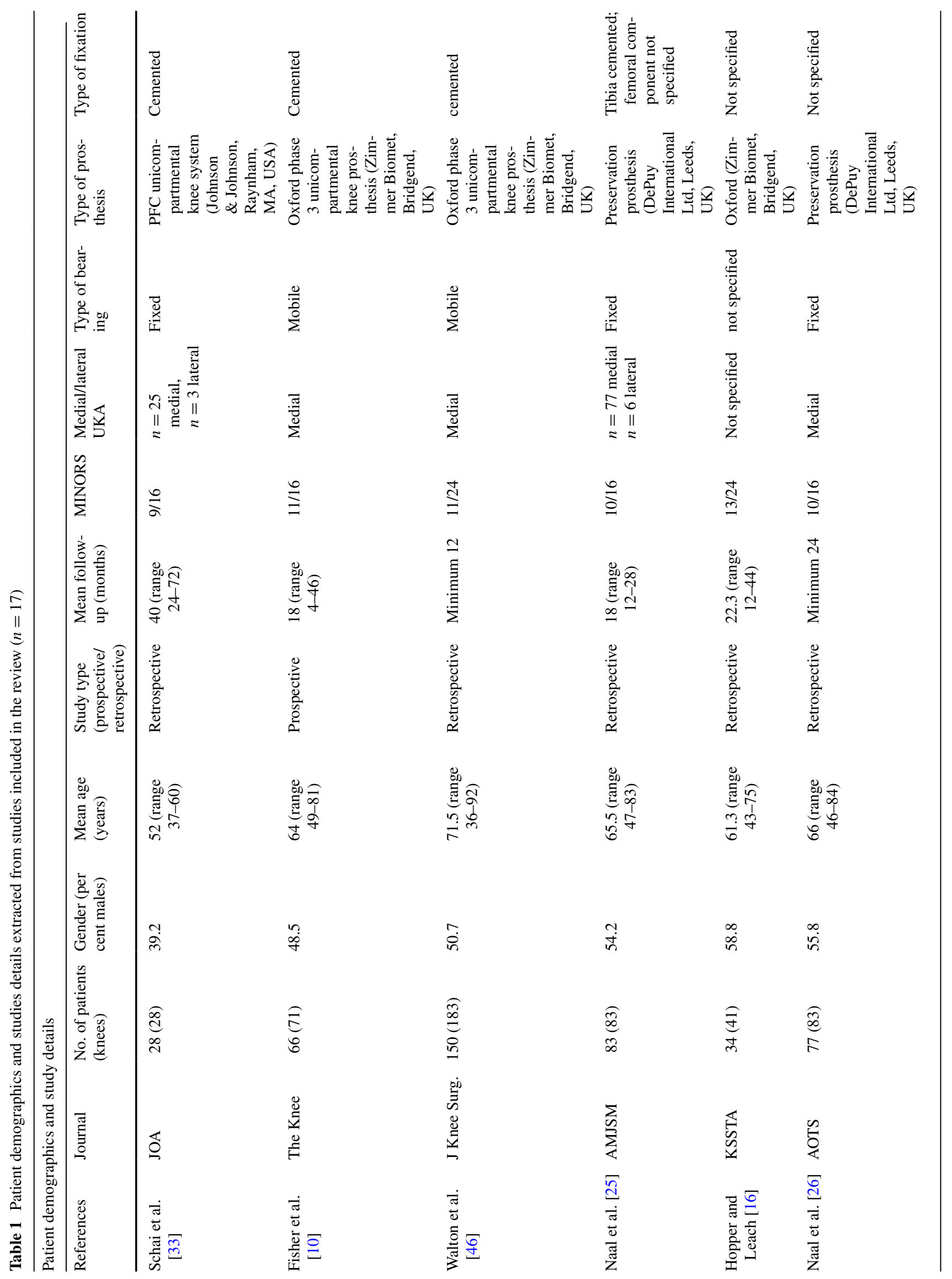




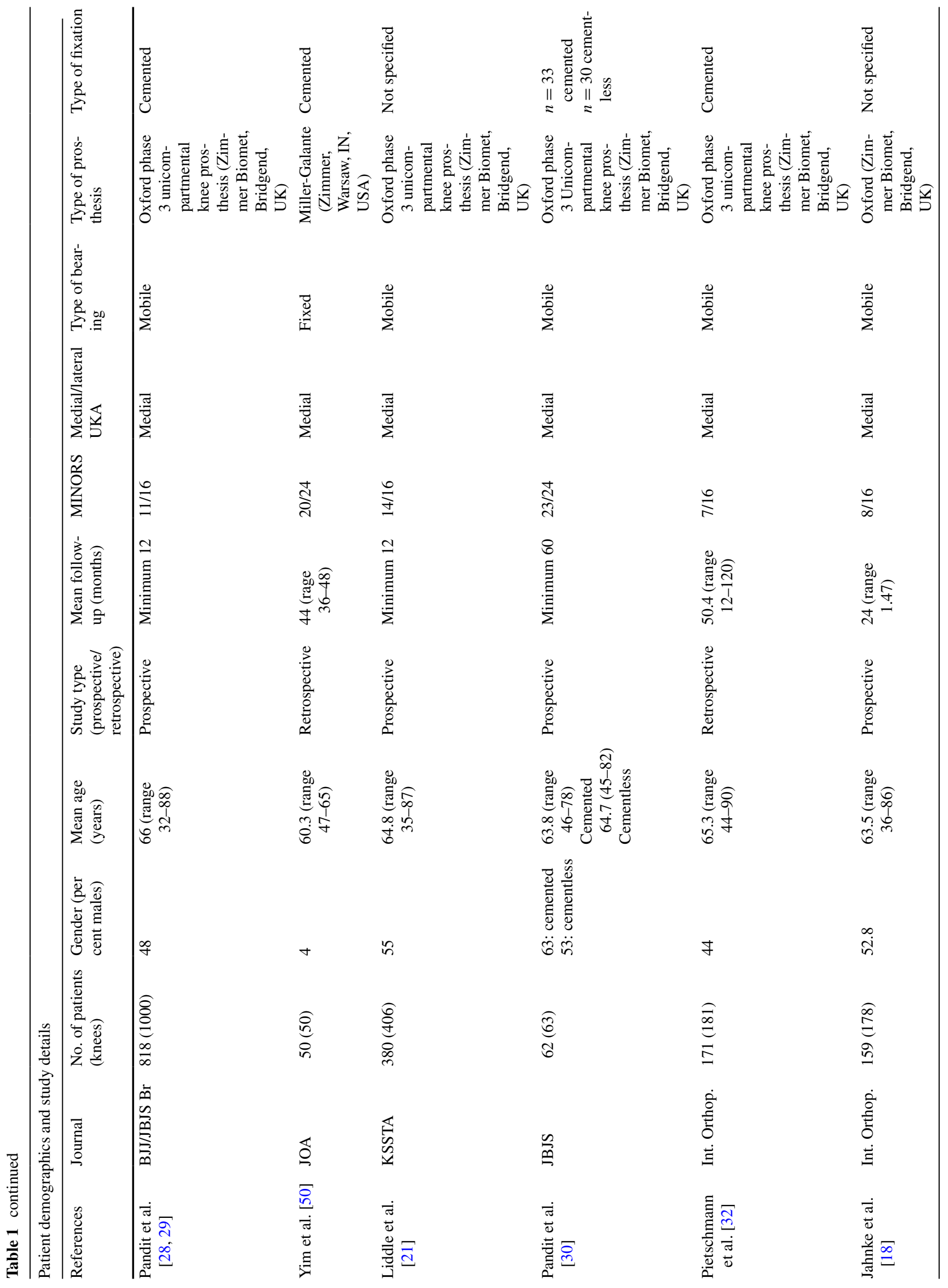




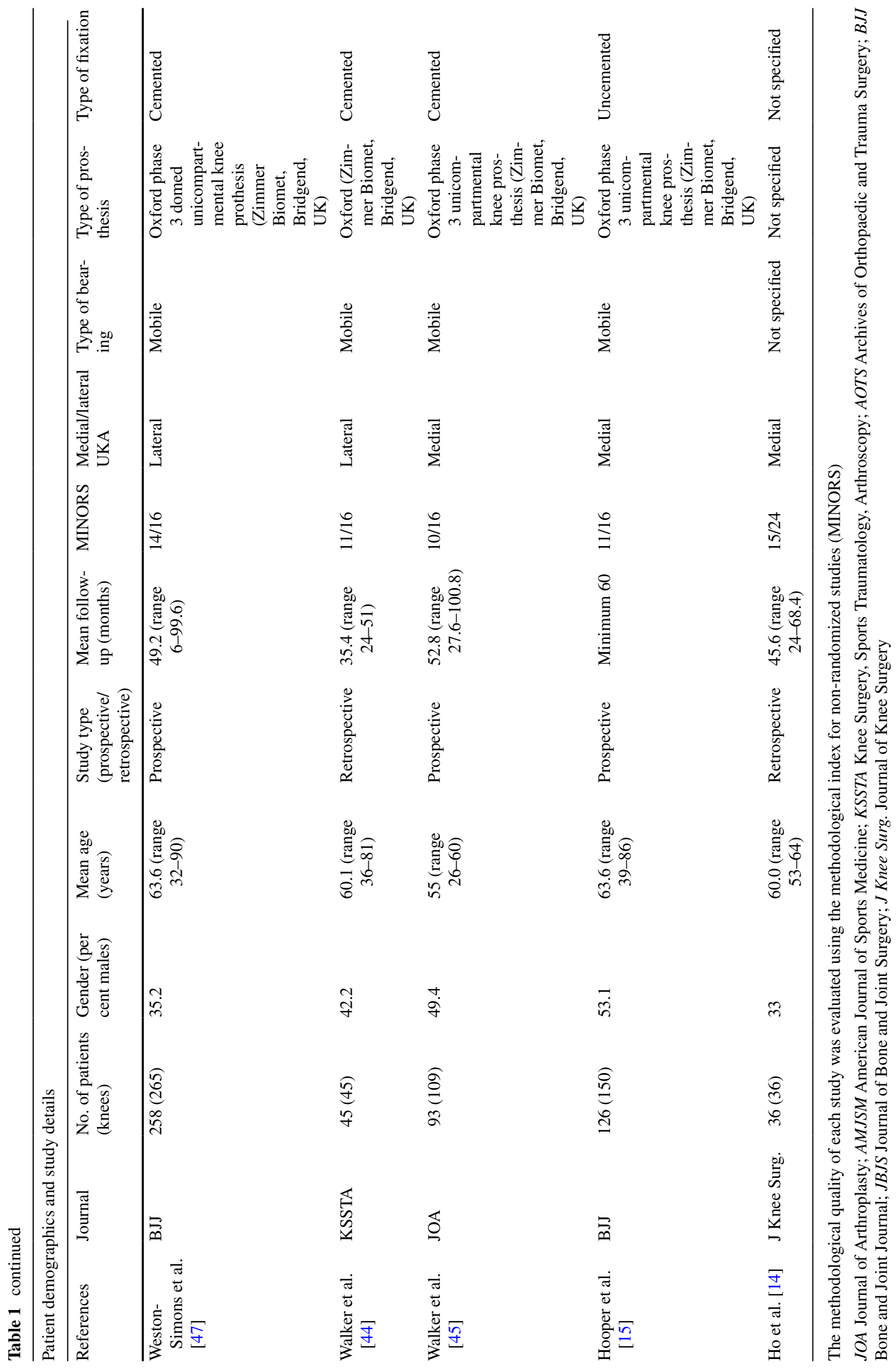


Fig. 1 Flow chart of study protocol following the PRISMA guidelines. The systematic review included 17 studies
Table 2 Methodological index for non-randomized studies (MINORS)

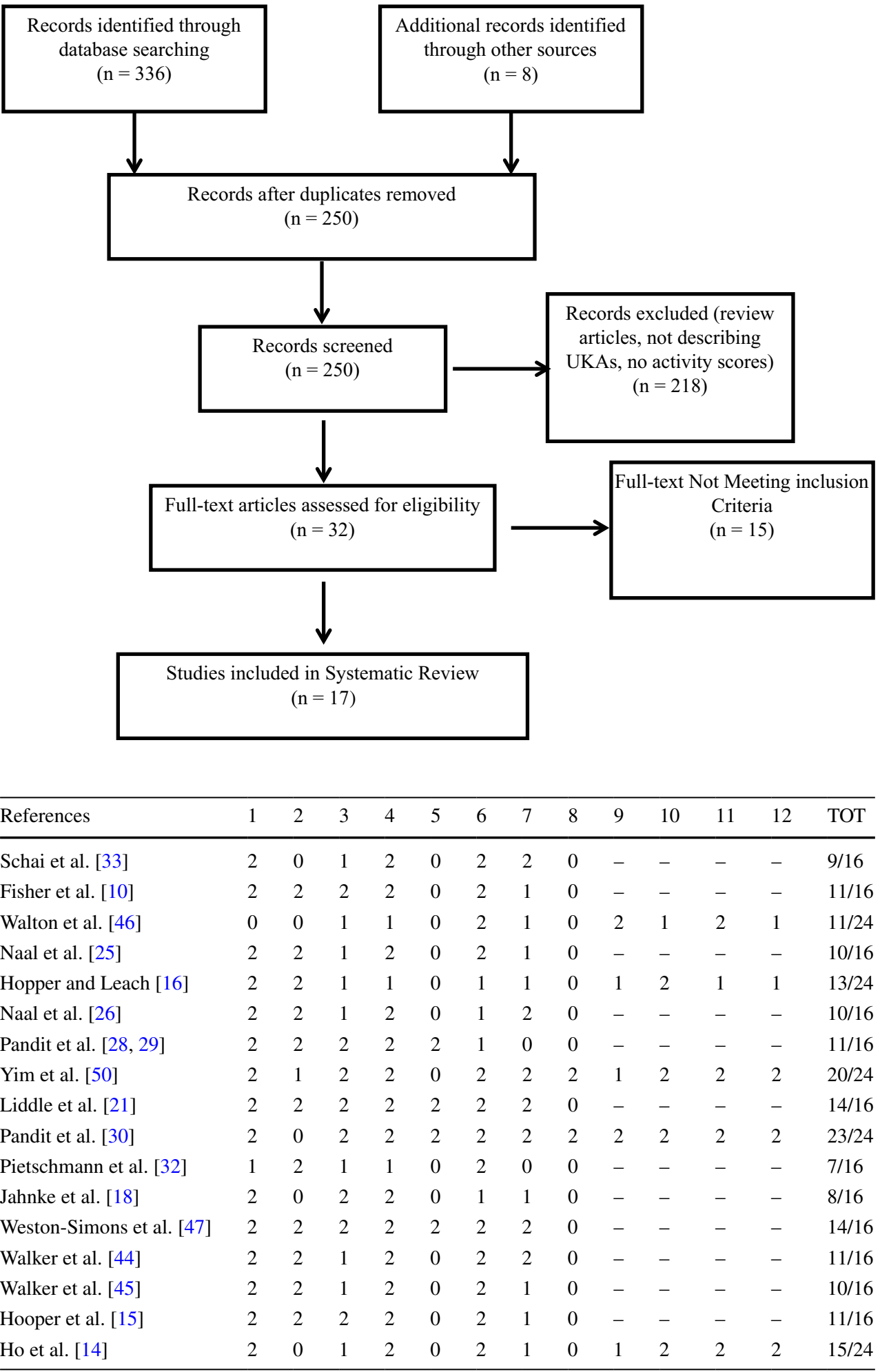

The methodological index for non-randomized studies (MINORS) applied to all studies assessing the level physical activity before and after implantation of a unicompartmental knee arthroplasty. The items are scored 0 (not reported), 1 (reported but inadequate) or 2 (reported and adequate)
Five studies described the UCLA activity score directly before surgery, and all these studies were able to demonstrate a significant improvement after UKA implantation
$[10,18,26,44,45]$. Only one study assessed the UCLA activity score before the onset of knee symptoms [14]. In comparison with pre-arthritic activity levels, the UCLA 
Table 3 Overview of pre- and post-operative activity scores and sport questionnaires of all studies analysed

\begin{tabular}{|c|c|c|c|c|c|c|}
\hline References & Journal & Outcome score(s) & $\begin{array}{l}\text { Pre-operative } \\
\text { assessment (time) }\end{array}$ & $\begin{array}{l}\text { Pre-operative } \\
\text { values }\end{array}$ & $\begin{array}{l}\text { Post-operative } \\
\text { values }\end{array}$ & Significance \\
\hline Schai et al. [33] & JOA & Tegner & Before surgery & 2.3 & 2.7 & Not calculated \\
\hline Fisher et al. [10] & The Knee & UCLA & Before surgery & 4.2 (range $3-6$ ) & 6.5 (range 3-9) & $p<0.01$ \\
\hline Walton et al. [46] & J Knee Surg. & $\begin{array}{l}\text { Simple sport ques- } \\
\text { tionnaire (no. of } \\
\text { disciplines) }\end{array}$ & Before surgery & N/A & N/A & Not calculated \\
\hline Naal et al. [25] & AMJSM & $\begin{array}{l}\text { Sport questionnaire } \\
\text { (no. of disci- } \\
\text { plines/frequency/ } \\
\text { session length) }\end{array}$ & $\begin{array}{l}\text { Before onset of } \\
\text { restricting symp- } \\
\text { toms }\end{array}$ & $5 / 2.9 / 66 \mathrm{~min}$ & $3.1 / 2.8 / 55 \mathrm{~min}$ & $p<0.01 / 0.329 / 0.08$ \\
\hline $\begin{array}{l}\text { Hopper and Leach } \\
\text { [16] }\end{array}$ & KSSTA & $\begin{array}{l}\text { Sport question- } \\
\text { naire (no. of } \\
\text { disciplines/fre- } \\
\text { quency per week/ } \\
\text { minimum session } \\
\text { length) }\end{array}$ & Before surgery & $1.5 / 3.2 / 85 \mathrm{~min}$ & $1.4 / 3.4 / 92.1 \mathrm{~min}$ & $\begin{array}{c}p=0.083 / p=0.727 / \\
p=0.487\end{array}$ \\
\hline Naal et al. [26] & AOTS & UCLA & Before surgery & $4.7 \pm 2.4$ & $7.1 \pm 1.9$ & $p<0.01$ \\
\hline $\begin{array}{l}\text { Pandit et al. [28, } \\
29]\end{array}$ & BJJ/JBJS Br & Tegner & Before surgery & $2.3 \pm 1.1$ & $\begin{array}{l}1 \text { year follow-up: } \\
2.9 \pm 0.9 \\
10 \text { years follow- } \\
\text { up: } 2 \pm 0.8\end{array}$ & Not calculated \\
\hline Yim et al. [50] & JOA & $\begin{array}{l}\text { Tegner, sport ques- } \\
\text { tionnaire (no. of } \\
\text { disciplines) }\end{array}$ & Before surgery & $\begin{array}{l}3.2 \pm 0.9 \\
2.2 \pm 1.6\end{array}$ & $\begin{array}{l}2.6 \pm 0.9 \\
1.6 \pm 1.7\end{array}$ & Not calculated \\
\hline Liddle et al. [21] & KSSTA & Tegner & Before surgery & $2.0(1-5)$ & $3.0(1-6)$ & $p<0.01$ \\
\hline Pandit et al. [30] & JBJS & Tegner & Before surgery & $\begin{array}{c}\text { Cemented: } \\
1.9 \pm 0.8 \\
\text { Cementless: } \\
1.9 \pm 0.7\end{array}$ & $\begin{array}{l}2.6 \pm 0.8 \\
2.9 \pm 0.6\end{array}$ & $\begin{array}{l}p<0.05 \\
p<0.05\end{array}$ \\
\hline $\begin{array}{l}\text { Pietschmann et al. } \\
\text { [32] }\end{array}$ & Int. Orthop. & $\begin{array}{l}\text { Sport question- } \\
\text { naire (no. of } \\
\text { disciplines/fre- } \\
\text { quency per week/ } \\
\text { minimum session } \\
\text { length) }\end{array}$ & Before surgery & $1.73 /-/-$ & $1.74 /-/-$ & Not calculated \\
\hline Jahnke et al. [18] & Int. Orthop. & $\begin{array}{l}\text { UCLA, Tegner, } \\
\text { Heidelberg Sports } \\
\text { Activity Score }\end{array}$ & Before surgery & $\begin{array}{l}6.2 \pm 1.3 \\
4.1 \pm 1.4 \\
23.8 \pm 18.5\end{array}$ & $\begin{array}{l}6.3 \pm 1.1 \\
4.0 \pm 1.0 \\
29.3 \pm 18.5\end{array}$ & $\begin{array}{l}p<0.01 \\
p=0.27 \\
p<0.01\end{array}$ \\
\hline $\begin{array}{l}\text { Weston-Simons } \\
\text { et al. [17] }\end{array}$ & BJJ & Tegner & Before surgery & $2.2 \pm 1.2$ & $2.9 \pm 1.2$ & $p<0.01$ \\
\hline Walker et al. [44] & KSSTA & $\begin{array}{l}\text { UCLA, Tegner, } \\
\text { Schulthess Clinic } \\
\text { Activity Score }\end{array}$ & $\begin{array}{l}\text { Before surgery } \\
\text { Before surgery } \\
\text { Before onset of } \\
\text { restricting symp- } \\
\text { toms }\end{array}$ & $\begin{array}{l}5.3 \pm 2.3 \\
2.9 \pm 1.6 \\
\text { N/A }\end{array}$ & $\begin{array}{l}6.7 \pm 1.5 \\
3.5 \pm 0.8 \\
\text { N/A }\end{array}$ & $\begin{array}{l}p<0.01 \\
p<0.01 \\
\text { N/A }\end{array}$ \\
\hline Walker et al. [45] & JOA & $\begin{array}{l}\text { UCLA, Tegner, } \\
\text { Schulthess Clinic } \\
\text { Activity Score }\end{array}$ & $\begin{array}{l}\text { Before surgery } \\
\text { Before surgery } \\
\text { Before onset of } \\
\text { restricting symp- } \\
\text { toms }\end{array}$ & $\begin{array}{l}3.3 \pm 1.5 \\
2.0 \pm 1.1 \\
\text { N/A }\end{array}$ & $\begin{array}{l}6.8 \pm 1.5 \\
3.8 \pm 1.1 \\
\text { N/A }\end{array}$ & $\begin{array}{l}p<0.001 \\
p<0.001 \\
\text { N/A }\end{array}$ \\
\hline Hooper et al. [15] & BJJ & $\begin{array}{l}\text { High Activity } \\
\text { Arthroplasty } \\
\text { Score }\end{array}$ & Before surgery & $4.33 \pm 2.5$ & $10.55 \pm 1.93$ & $p<0.001$ \\
\hline
\end{tabular}


Table 3 continued

\begin{tabular}{|c|c|c|c|c|c|c|}
\hline \multicolumn{7}{|c|}{ Activity scores and sport questionnaires } \\
\hline References & Journal & Outcome score(s) & $\begin{array}{l}\text { Pre-operative } \\
\text { assessment (time) }\end{array}$ & $\begin{array}{l}\text { Pre-operative } \\
\text { values }\end{array}$ & $\begin{array}{l}\text { Post-operative } \\
\text { values }\end{array}$ & Significance \\
\hline Ho et al. [14] & J Knee Surg. & UCLA & $\begin{array}{l}\text { Before onset of } \\
\text { restricting symp- } \\
\text { toms }\end{array}$ & $8.1 \pm 1.5$ & $7.4 \pm 1.6$ & Not calculated \\
\hline
\end{tabular}

JOA Journal of Arthroplasty; AMJSM American Journal of Sports Medicine; KSSTA Knee Surgery, Sports Traumatology, Arthroscopy; AOTS Archives of Orthopaedic and Trauma Surgery; BJJ Bone and Joint Journal; JBJS Journal of Bone and Joint Surgery; J Knee Surg. Journal of Knee Surgery

activity score slightly decreased from 8.1 to 7.4 points following UKA. Despite the slight decrease in activity levels, patients still had the highest UCLA activity score of all studies analysed [14] (Table 3).

Overall, nine studies used the Tegner activity score to describe the pre- and post-operative level of physical activity. Five studies reported a statistically significant improvement following UKA [21, 30, 44, 45, 47]. The remaining four studies did either show no statistical difference [18] or did not calculate a significance level, respectively [29, 33, 50]. Jahnke et al. [18] described no statistically significant difference (n.s.) in the Tegner activity score comparing preand post-operative levels. The mean pre-operative Tegner activity score in Jahnkes' study was considerably higher (4.1) compared to the remaining studies using this score (Table 3). Patient demographics did not differ compared to the other studies. The reason for the high pre-operative Tegner score, therefore, cannot be explained. Schai et al. [33] reported a relative improvement from 2.3 to 2.7 points according to the Tegner activity score, without calculating a significance level. Pandit et al. [29] also described the Tegner activity score in their study of 1000 consecutive Oxford UKAs with a minimum follow-up of 10 years. There was an improvement of the pre-operative Tegner activity score up to 7 years post-operatively; however, the score decreased below pre-operative levels at 10 years. Pandit et al. [29] did not calculate any significance level. Only Yim et al. [50] described a decrease in the Tegner activity score following UKA. However, a significance level was not calculated. Yim et al. [50] described a cohort of $96 \%$ (48 of 50) female patients (Table 3 ).

In a recent study on 150 consecutive cementless UKAs, Hooper et al. [15] were able to demonstrate a significant improvement according to the High Activity Arthroplasty Score following UKA (Table 3).

\section{Sport disciplines, length and frequency}

Seven out of 17 studies described the level of physical activity in more detail, using either standardized [18, 44, $45]$ or non-standardized questionnaires [10, 25, 32, 50].
Using the Heidelberg Sports Activity Score, Jahnke et al. [18] reported that hiking, cycling and swimming were the three most practiced sports after surgery. Swimming, hiking and 'other sports' increased significantly. Highimpact sports such as skiing, cross-country skiing and ball sports decreased significantly compared to pre-operatively practiced sports. Walker et al. [44] showed that biking, hiking and long walks were the most common activities after surgery according to the Schulthess Clinic Activity Score. Similar to Jahnke et al., a significant decrease in more intense activities such as tennis, soccer, jogging or skiing was observed after UKA implantation. In a further analysis of patients younger than 60 years, Walker et al. [45] reported a significant decrease in high-impact activities and a significant increase in low-impact activities after surgery, respectively.

Five studies reported physical activities based on individually developed scores. Naal et al. [25] described the physical activity using an individual score which recorded the number of activities, its frequency and the session length. The authors report an unchanged activity frequency after surgery with similar session length and a slight, although significant, decrease in the number of different sport disciplines (Table 3). The most common activities after surgery were hiking, cycling and swimming. Hopper et al. [16] analysed the participation in the following disciplines: golf, swimming, dancing (line/ballroom), bowls and cycling. The authors showed that the number of activities, its frequency and the session length remained unchanged with a UKA (Table 3). Yim et al. [50] assessed the participation in cycling, swimming, exercise walking, dancing, jogging and mountain climbing, and described a return to 1.6 activities after surgery compared to 2.2 activities before surgery, respectively. Fisher et al. [10] showed that most patients $(93 \%)$ following UKA resumed the same physical activity they performed before becoming symptomatic with knee pain. The top three activities were swimming, golf and dancing in Fishers' study. Pietschmann et al. [32] described the percentage of patients who performed sports activities before $(60 \%)$ and after $(53 \%)$ surgery. The authors, furthermore, reported on an increase in the weekly 
Table 4 Summary of the reported pre- and post-operative sport participation rate and the return to activity rate of all studies analysed

\begin{tabular}{|c|c|c|c|c|}
\hline \multicolumn{5}{|c|}{ Pre-operative and post-operative sport participation } \\
\hline References & $\begin{array}{l}\text { Time of pre-operative } \\
\text { assessment }\end{array}$ & $\begin{array}{l}\text { Pre-operative sport } \\
\text { participation }\end{array}$ & $\begin{array}{l}\text { Post-operative sport } \\
\text { participation }\end{array}$ & Return to activity rate \\
\hline Fisher et al. [10] & Before onset of knee pain & $64 \%(42$ of 66$)$ & $59 \%(39$ of 66$)$ & $93 \%$ \\
\hline Walton et al. [46] & Directly before surgery & $79 \%(121$ of 150$)$ & $86 \%(131$ of 131$)$ & Not described \\
\hline Naal et al. [25] & Before onset of knee pain & $93 \%(77$ of 83$)$ & $88 \%(73$ of 83$)$ & $95 \%$ \\
\hline Hopper and Leach [16] & Directly before surgery & $88 \%(30$ of 34$)$ & $85 \%(29$ of 34$)$ & $97 \%$ \\
\hline Yim et al. [50] & Directly before surgery & $84 \%(42$ of 50$)$ & $60 \%(30$ of 50$)$ & Not described \\
\hline Pietschmann et al. [32] & Directly before surgery & $60 \%(78$ of 131$)$ & $53 \%(69$ of 131$)$ & $80 \%$ \\
\hline Jahnke et al. (2014) & Directly before surgery & $90 \%$ & $93 \%$ & Not described \\
\hline Walker et al. [44] & Before onset of knee pain & $93 \%(42$ of 45$)$ & $91 \%(43$ of 45$)$ & $98 \%$ \\
\hline Walker et al. [45] & Before onset of knee pain & $93 \%(86$ of 93$)$ & $91 \%(85$ of 93$)$ & $93 \%$ \\
\hline Ho et al. [14] & Before onset of knee pain & $83 \%(30$ of 36$)$ & $72 \%(26$ of 36$)$ & $87 \%$ \\
\hline
\end{tabular}

Patients with a unicompartmental knee arthroplasty participate regularly in sports

sport frequency after UKA and a shift from high-impact sports towards low-impact sports, respectively.

\section{Sport participation and return to activity}

The pre-operative and post-operative sport participation was described in ten studies $[10,14,16,18,25,32,44-46$, 50]. The sport participation before the onset of restricting symptoms of the knee was reported in five studies, and ranged from 64 to $93 \%$, respectively [10, 14, 25, 44, 45]. In all five studies, patients stayed active; however, sport participation decreased up to $9 \%$ compared to pre-arthritic conditions (Table 4). Seven studies described the return to activity rate which ranged from 80 to $98 \%[10,14,16,25$, 32, 44, 45] (Table 4).

\section{Discussion}

The most important findings of the present study were that the level of physical activity improves following UKA implantation according to established activity scores. A shift from high-impact to low-impact activities was observed. The number of different sport activities decreased, whereas the session length und frequency remained overall unchanged.

The UCLA activity score is validated activity assessment tool for patients with joint arthroplasties of the lower extremities $[1,51]$. The present review demonstrates that in all but one study $(n=5)$ the UCLA activity score significantly improved following UKA implantation. The mean postoperative UCLA activity score ranged from 6.3 to 7.4 points. An UCLA activity score of 7 corresponds with the regular participation in active events such as bicycling. One study assessing the UCLA activity score before the onset of first restricting symptoms reported a slight decrease in the activity level compared to pre-arthritic conditions [14]. The study, however, still demonstrated the highest UCLA activity score of all studies analysed [14]. Overall, patients following UKA remain active according to the UCLA activity score.

The Tegner activity rating system was initially developed to evaluate activity after knee ligament injuries [38]. The Tegner and the UCLA activity scores both have a scale of 1-10 points. The Tegner score, however, is usually used for more active patient populations like ACL reconstruction patients. A Tegner score of 10, for instance, corresponds with competitive sports such as soccer on a national or international level. The mean post-operative Tegner activity score of all studies analysed in this review was 3.1 points which corresponds with competitive and recreational sports such as swimming. The fact that in some studies the Tegner score did not show statistically significant improvements following surgery is partly explained by the larger bandwidth of activities described in the Tegner activity score. The practiced activities have the change a lot to move from a Tegner activity score of 3 to a score of 4, while an improvement from level 3 to level 4 is easy on UCLA activity rating scale, respectively.

Eight out of 17 studies described the level of physical activity in more detail. All studies, irrespective of the questionnaire utilized, showed a significant decrease in highimpact activities and a significant increase in low-impact activities. The most popular activities after surgery were hiking, cycling and swimming. Almost all activities were in line with recommendations for the return to recreational and athletic activity after TKA presented by the Knee Society [12]. Naal et al. [25] reported on an active Swiss patient population of which $22 \%$ performed downhill skiing following surgery. The Knee Society has not come to a conclusion whether downhill skiing should be recommended [13]. 
Although patients took up lower-impact activities, its frequency per week and the minimum session length even increased [16] or remained unchanged [25, 32]. The only study describing a decrease in activities was published by Yim et al. [50]. Interestingly, this study described an Asian cohort with $96 \%$ (48 of 50) female patients. However, the reason for a decrease in physical activities according to the Tegner score and a sport questionnaire remains unknown.

There has been a lot of debate whether mobile-bearing designs offer a clinical advantage over fixed-bearing designs because of decreased wear rates and reduced shear stress at the interfaces [35]. However, a recent meta-analysis showed that there are no differences in the clinical outcome; and in experienced hands, revision rates are comparable [31]. The current review included four studies with fixed-bearing UKAs, and no differences in the level of post-operative physical activities were observed [25, 26, 33, 50].

Two studies reported on the level of sport and physical activity following lateral UKA [44, 47]. Both studies demonstrated a highly significant improvement of post-operative physical activity according to the UCLA and Tegner activity score, respectively.

Witjes et al. [49] recently published a literature review describing pre- and/or post-operative participation in specific types of sports and/or the time to return to sport after TKA and/or UKA. The authors concluded that participation in sports seems more likely after UKA than after TKA, and patients tend to return to lower-impact types of sport. This review is in line with these observations. However, the current review provides additional information as it included all available studies that described the level of activity utilizing scores commonly used in clinical practice.

There are a number of limitations that warrant acknowledgment. Firstly, only 8 of the 17 studies included were prospectively designed; hence, the level of evidence currently available is not particularly high. It cannot be ignored that retrospective studies may be influenced by various bias-inducing factors. Second, 12 out of 17 studies (2398 of 2636 patients) reported on the Oxford phase 3 unicompartmental knee implant. Therefore, the conclusions of this review are primarily valid for this particular type of implant. Third, most studies, with exception of Pandit et al. [29], were quite small in terms of patient numbers. Finally, the minimum follow-up was $<2$ years in eight studies. However, in an attempt to increase the number of studies, these studies were not excluded.

In clinical practice, this systematic review may help physicians to manage the expectations of patients regarding the level of physical activity following UKA. Eleven out of thirteen studies described a post-operative increase in physical activity according to validated activity scores. Almost all activities were in line with Knee Society recommendations for the return to recreational and athletic activity.
Even though patients have increasing demands, this report suggests that patients do not participate in high-level sports following UKA. The reason for a limitation of sport activities remained unclear in most studies. Only Walker et al. [44] described that the preservation of the implant was the main reason for a limitation of activities.

Additionally, this study allows surgeons performing UKAs to compare their results with the results published in the literature.

\section{Conclusion}

Patients following UKA are active according to validated activity scores. A significant increase in low-impact activities and a decrease in high-impact activities after UKA was observed. The number of different sport activities decreased, whereas the session length und frequency remained overall unchanged. Patients with a UKA regularly participate in sport, however, sport participation slightly decreased compared to pre-arthritic levels.

Acknowledgments Open access funding provided by Medical University of Vienna.

Authors' contributions WW drafted the study, directly supervised the systematic review and finalized the manuscript. PK performed the systematic review and drafted the manuscript. UK revised the manuscript and supported the review process. FB provided suggestions on the review process and wrote substantial parts of the manuscript. RW analysed the data and contributed to the manuscript. All authors read and approved the final manuscript.

\section{Compliance with ethical standards}

Competing interests The authors declare that they have no competing interests.

Open Access This article is distributed under the terms of the Creative Commons Attribution 4.0 International License (http://creativecommons.org/licenses/by/4.0/), which permits unrestricted use, distribution, and reproduction in any medium, provided you give appropriate credit to the original author(s) and the source, provide a link to the Creative Commons license, and indicate if changes were made.

\section{Appendix}

The following search terms were used on MEDLINE:

1. UKA.

2. (activity, physical[MeSH Terms] OR activity, motor[MeSH Terms] OR sports[MeSH Terms] OR sports OR sport OR (motor AND activity) OR motor activity OR physical activity OR activity).

3. 1. AND 2 . 


\section{References}

1. Amstutz HC, Thomas BJ, Jinnah R, Kim W, Grogan T, Yale C (1984) Treatment of primary osteoarthritis of the hip. A comparison of total joint and surface replacement arthroplasty. J Bone Joint Surg Am 66(2):228-241

2. Biswas D, Van Thiel GS, Wetters NG, Pack BJ, Berger RA, Della Valle CJ (2014) Medial unicompartmental knee arthroplasty in patients less than 55 years old: minimum of two years of followup. J Arthroplasty 29(1):101-105

3. Bruni D, Akkawi I, Iacono F, Raspugli GF, Gagliardi M, Nitri M, Grassi A, Zaffagnini S, Bignozzi S, Marcacci M (2013) Minimum thickness of all-poly tibial component unicompartmental knee arthroplasty in patients younger than 60 years does not increase revision rate for aseptic loosening. Knee Surg Sports Traumatol Arthrosc 11:2462-2467

4. Callaghan JJ (2005) Unicompartmental knee replacement: introduction: where have we been? Where are we now? Where are we going? Clin Orthop Relat Res 430:272-273

5. Cartier P, Khefacha A, Sanouiller JL, Frederick K (2007) Unicondylar knee arthroplasty in middle-aged patients: a minimum 5-year follow-up. Orthopedics 30(8 Suppl.):62-65

6. Davis MA, Ettinger WH, Neuhaus JM, Mallon KP (1991) Knee osteoarthritis and physical functioning: evidence from the NHANES I Epidemiologic Followup Study. J Rheumatol 18(4):591-598

7. Deschamps G, Chol C (2011) Fixed-bearing unicompartmental knee arthroplasty. Patients' selection and operative technique. Orthop Traumatol Surg Res 97(6):648-661

8. Deshmukh RV, Scott RD (2002) Unicompartmental knee arthroplasty for younger patients: an alternative view. Clin Orthop Relat Res 404:108-112

9. Ettinger WH Jr, Fried LP, Harris T, Shemanski L, Schulz R, Robbins J (1994) Self-reported causes of physical disability in older people: the Cardiovascular Health Study. CHS Collaborative Research Group. J Am Geriatr Soc 42(10):1035-1044

10. Fisher N, Agarwal M, Reuben SF, Johnson DS, Turner PG (2006) Sporting and physical activity following Oxford medial unicompartmental knee arthroplasty. Knee 13(4):296-300

11. Goodfellow JW, O'Connor J, Dodd CA, Murray DW (2006) Unicompartmental arthroplasty with the Oxford knee. Oxford University Press, Oxford

12. Healy WL, Iorio R, Lemos MJ (2000) Athletic activity after total knee arthroplasty. Clin Orthop Relat Res 380:65-71

13. Healy WL, Iorio R, Lemos MJ (2001) Athletic activity after joint replacement. Am J Sports Med 29(3):377-388

14. Ho JC, Stitzlein RN, Green CJ, Stoner T, Froimson MI (2016) Return to sports activity following UKA and TKA. J Knee Surg 29(3):254-259

15. Hooper N, Snell D, Hooper G, Maxwell R, Frampton C (2015) The five-year radiological results of the uncemented Oxford medial compartment knee arthroplasty. Bone Joint J 97-B(10):1358-1363

16. Hopper GP, Leach WJ (2008) Participation in sporting activities following knee replacement: total versus unicompartmental. Knee Surg Sports Traumatol Arthrosc 16(10):973-979

17. Insall JN, Dorr LD, Scott RD, Scott WN (1989) Rationale of the Knee Society clinical rating system. Clin Orthop Relat Res 248:13-14

18. Jahnke A, Mende JK, Maier GS, Ahmed GA, Ishaque BA, Schmitt H, Rickert M, Clarius M, Seeger JB (2015) Sports activities before and after medial unicompartmental knee arthroplasty using the new Heidelberg Sports Activity Score. Int Orthop 39(3):449-454

19. Kozinn SC, Scott R (1989) Unicondylar knee arthroplasty. J Bone Joint Surg Am 71(1):145-150
20. Kurtz S, Ong K, Lau E, Mowat F, Halpern M (2007) Projections of primary and revision hip and knee arthroplasty in the United States from 2005 to 2030. J Bone Joint Surg Am 89(4):780-785

21. Liddle AD, Pandit H, Jenkins C, Price AJ, Dodd CA, Gill HS, Murray DW (2013) Preoperative pain location is a poor predictor of outcome after Oxford unicompartmental knee arthroplasty at 1 and 5 years. Knee Surg Sports Traumatol Arthrosc 21(11):2421-2426

22. Moher D, Liberati A, Tetzlaff J, Altman DG (2009) Preferred reporting items for systematic reviews and meta-analyses: the PRISMA statement. PLoS Med 6(7):e1000097

23. Murphy L, Schwartz TA, Helmick CG, Renner JB, Tudor G, Koch G, Dragomir A, Kalsbeek WD, Luta G, Jordan JM (2008) Lifetime risk of symptomatic knee osteoarthritis. Arthritis Rheum 59(9):1207-1213

24. Murray DW, Liddle A, Dodd CA, Pandit H (2015) Unicompartmental knee arthroplasty: is the glass half full or half empty? Bone Joint J 97-B(10 Suppl. A):3-8

25. Naal FD, Fischer M, Preuss A, Goldhahn J, von Knoch F, Preiss S, Munzinger U, Drobny T (2007) Return to sports and recreational activity after unicompartmental knee arthroplasty. Am J Sports Med 35(10):1688-1695

26. Naal FD, Neuerburg C, Salzmann GM, Kriner M, von Knoch F, Preiss S, Drobny T, Munzinger U (2009) Association of body mass index and clinical outcome 2 years after unicompartmental knee arthroplasty. Arch Orthop Trauma Surg 129(4):463-468

27. O'Rourke MR, Gardner JJ, Callaghan JJ, Liu SS, Goetz DD, Vittetoe DA, Sullivan PM, Johnston RC (2005) The John Insall Award: unicompartmental knee replacement: a minimum twenty-one-year followup, end-result study. Clin Orthop Relat Res 440:27-37

28. Pandit H, Gulati A, Jenkins C, Barker K, Price AJ, Dodd CA, Murray DW (2011) Unicompartmental knee replacement for patients with partial thickness cartilage loss in the affected compartment. Knee 18(3):168-171

29. Pandit H, Jenkins C, Gill HS, Barker K, Dodd CA, Murray DW (2011) Minimally invasive Oxford phase 3 unicompartmental knee replacement: results of 1000 cases. J Bone Joint Surg Br 93(2):198-204

30. Pandit H, Liddle AD, Kendrick BJ, Jenkins C, Price AJ, Gill HS, Dodd CA, Murray DW (2013) Improved fixation in cementless unicompartmental knee replacement: five-year results of a randomized controlled trial. J Bone Joint Surg Am 95(15):1365-1372

31. Peersman G, Stuyts B, Vandenlangenbergh T, Cartier P, Fennema P (2015) Fixed- versus mobile-bearing UKA: a systematic review and meta-analysis. Knee Surg Sports Traumatol Arthrosc 23(11):3296-3305

32. Pietschmann MF, Wohlleb L, Weber P, Schmidutz F, Ficklscherer A, Gulecyuz MF, Safi E, Niethammer TR, Jansson V, Muller PE (2013) Sports activities after medial unicompartmental knee arthroplasty Oxford III-what can we expect? Int Orthop 37(1):31-37

33. Schai PA, Suh JT, Thornhill TS, Scott RD (1998) Unicompartmental knee arthroplasty in middle-aged patients: a 2- to 6-year follow-up evaluation. J Arthroplasty 13(4):365-372

34. Slim K, Nini E, Forestier D, Kwiatkowski F, Panis Y, Chipponi J (2003) Methodological index for non-randomized studies (minors): development and validation of a new instrument. ANZ J Surg 73(9):712-716

35. Smith TO, Hing CB, Davies L, Donell ST (2009) Fixed versus mobile bearing unicompartmental knee replacement: a metaanalysis. Orthop Traumatol Surg Res 95(8):599-605

36. Streit MR, Streit J, Walker T, Bruckner T, Philippe Kretzer J, Ewerbeck V, Merle C, Aldinger PR, Gotterbarm T (2015) Minimally invasive Oxford medial unicompartmental knee 
arthroplasty in young patients. Knee Surg Sports Traumatol Arthrosc. doi:10.1007/s00167-015-3620-x

37. Streit MR, Walker T, Bruckner T, Merle C, Kretzer JP, Clarius M, Aldinger PR, Gotterbarm T (2012) Mobile-bearing lateral unicompartmental knee replacement with the Oxford domed tibial component: an independent series. J Bone Joint Surg Br 94(10):1356-1361

38. Tegner Y, Lysholm J (1985) Rating systems in the evaluation of knee ligament injuries. Clin Orthop Relat Res 198:43-49

39. Verbrugge LM, Lepkowski JM, Konkol LL (1991) Levels of disability among U.S. adults with arthritis. J Gerontol 46(2):S71-S83

40. Von Keudell A, Sodha S, Collins J, Minas T, Fitz W, Gomoll AH (2014) Patient satisfaction after primary total and unicompartmental knee arthroplasty: an age-dependent analysis. Knee 21(1):180-184

41. Vorlat P, Putzeys G, Cottenie D, Van Isacker T, Pouliart N, Handelberg F, Casteleyn PP, Gheysen F, Verdonk R (2006) The Oxford unicompartmental knee prosthesis: an independent 10-year survival analysis. Knee Surg Sports Traumatol Arthrosc 14(1):40-45

42. Waldstein W, Bou Monsef J, Buckup J, Boettner F (2013) The value of valgus stress radiographs in the workup for medial unicompartmental arthritis. Clin Orthop Relat Res 471(12):3998-4003

43. Waldstein W, Merle C, Bou Monsef J, Boettner F (2015) Varus knee osteoarthritis: how can we identify ACL insufficiency? Knee Surg Sports Traumatol Arthrosc 23(8):2178-2184

44. Walker T, Gotterbarm T, Bruckner T, Merle C, Streit MR (2015) Return to sports, recreational activity and patient-reported outcomes after lateral unicompartmental knee arthroplasty. Knee Surg Sports Traumatol Arthrosc 23(11):3281-3287

45. Walker T, Streit J, Gotterbarm T, Bruckner T, Merle C, Streit MR (2015) Sports, physical activity and patient-reported outcomes after medial unicompartmental knee arthroplasty in young patients. J Arthroplasty 30(11):1911-1916

46. Walton NP, Jahromi I, Lewis PL, Dobson PJ, Angel KR, Campbell DG (2006) Patient-perceived outcomes and return to sport and work: TKA versus mini-incision unicompartmental knee arthroplasty. J Knee Surg 19(2):112-116

47. Weston-Simons JS, Pandit H, Kendrick BJ, Jenkins C, Barker K, Dodd CA, Murray DW (2014) The mid-term outcomes of the Oxford domed lateral unicompartmental knee replacement. Bone Joint J 96-B(1):59-64

48. White SH, Ludkowski PF, Goodfellow JW (1991) Anteromedial osteoarthritis of the knee. J Bone Joint Surg Br 73(4):582-586

49. Witjes S, Gouttebarge V, Kuijer PP, van Geenen RC, Poolman RW, Kerkhoffs GM (2016) Return to sports and physical activity after total and unicondylar knee arthroplasty: a systematic review and meta-analysis. Sports Med 46(2):269-292

50. Yim JH, Song EK, Seo HY, Kim MS, Seon JK (2013) Comparison of high tibial osteotomy and unicompartmental knee arthroplasty at a minimum follow-up of 3 years. J Arthroplasty 28(2):243-247

51. Zahiri CA, Schmalzried TP, Szuszczewicz ES, Amstutz HC (1998) Assessing activity in joint replacement patients. J Arthroplasty 13(8):890-895 